\title{
Pesquisa em Atenção Primária à Saúde
}

\author{
Research in Primary Health Care \\ Investigación en Atención Primaria de Salud
}

Armando Henrique Norman. MSc em Antropologia Médica pela Durham University. editor.rbmfc@sbmfc.org.br

De acordo com a maioria das organizações profissionais e de saúde, a atenção primária inclui o primeiro contato, assim como a continuidade, abrangência e coordenação do cuidado. Tanto do ponto de vista da população como do indivíduo, um sistema de saúde que procure alcançar esses quatro elementos estará realizando o que foi proposto pela Declaração de Alma Ata.

Barbara Starfield ${ }^{1}$

A edição 27 da RBMFC traz temas interessantes para a prática do Médico de Família e Comunidade. Na seção Ensaios, o artigo Desenvolvimento e formação profissional em Medicina Geral e de Família na Alemanha analisa o processo de formação dos MFCs na Alemanha, identificando suas características e instrumentos de intervenção, bem como descreve as exigências para a especialização em medicina de família, analisando o processo de qualificação da especialidade naquele país. Segundo os autores, o desenvolvimento da medicina de família na Alemanha significou "intenso processo de academização, com a criação de departamentos de medicina de família em 20 das 36 faculdades públicas de medicina do país”. Esse fato reforça o tema trabalhado na edição 26 da RBMFC e prepara para a discussão que se segue: a pesquisa na Atenção Primária à Saúde (APS).

Para realizar pesquisa na APS necessita-se criar redes que integrem órgãos fomentadores (fundos para pesquisa), instituiçôes de ensino (universidades) e os profissionais dos serviços da APS². Essa integração, que ocorreu em países como Canadá, Inglaterra, Alemanha e Espanha, fortaleceu a APS e valorizou a especialidade e os profissionais vinculados a ela. Assim, o tema da pesquisa em APS perpassa a academização da especialidade Medicina de Família e Comunidade (MFC). Outro fator consequente desse processo de academização da MFC é o favorecimento de linhas mais claras de fomento à pesquisa para a APS, com vistas a melhorar a qualidade, a efetividade e a relação custo-efetividade de seus serviços, em todas as suas manifestaçóes. Nesse sentido, Jones ${ }^{2}$ destaca três grandes eixos a serem abordados: a) Quando os serviços em APS são frágeis, as pesquisas devem responder à questôes de como fortalecê-los; b) Quando existirem diferenças nos padrôes dos serviços oferecidos, bem como diferenças no desempenho e comportamento dos profissionais, a pesquisa deve focar nas suas razóes e em como fazer para melhorar este cenário; c) Quando houver dúvida quanto à efetividade das intervenções ofertadas nos serviços da APS, a pesquisa deve responder a essa questão de modo a fornecer bases científicas (ou evidências) para a adoção ou não das intervençôes. É importante reforçar que essas questôes devem ser levantadas a partir da realidade, para que as pesquisas em APS possam contribuir para alta qualidade, efetividade e custo-efetividade dos cuidados em saúde. Assim, os resultados das pesquisas, quando transformados em políticas públicas ou guias clínicos (protocolos), teriam um maior potencial, tanto para atender às necessidades dos serviços e da população (to scratch where it itches) ${ }^{3}$, quanto para serem realmente transformadores da realidade ${ }^{4}$. 
Convém destacar que os problemas de saúde com os quais os médicos de família se deparam no cotidiano dos serviços da APS estão imbricados em uma diversidade socioeconômica e cultural que é indissociável da sua prática. Nesse sentido pode-se dizer que a pesquisa em APS requer uma abordagem mais "ecológica" do que reducionista da ciência, o que implica em um aporte das Ciências Sociais 5 .

Dentro dessa dimensão do cuidado, os médicos de família lidam com problemas prevalentes na comunidade e com casos indiferenciados, cujo processo de trabalho requer uma outra forma de classificação para melhor cuidar e estudar a realidade apresentada ${ }^{6}$. Face a esse contexto, os médicos de família desenvolveram um sistema de classificação denominado Classificação Internacional da Atenção Primária (CIAP), mais vinculado ao processo de trabalho como um todo do que à Classificação Internacional das Doenças (CID), que se relaciona mais ao processo de vigilância da morbimortalidade. A CIAP, atualmente na sua segunda versão, classifica o processo de cuidado em três diferentes segmentos: razão de encontro, diagnóstico e processo ${ }^{7}$. Assim, a CIAP-2 possibilita ao clínico ou pesquisador mudar para uma epidemiologia orientada ao episódio do cuidado, ou seja, permite uma análise ao longo do tempo do episódio de cuidado, na medida que esse se desenvolve, marcado pela transição (ou mudanças) na relação entre a razão do encontro ou consulta, diagnóstico e intervençóes realizadas. A CIAP-2 também é mais leve e com poucos códigos, se comparada ao CID, pois abarca os problemas mais comuns da prática, com frequência intermediária (definidos por taxa de ocorrência de 1-5/1.000 pacientes/ano) ou frequentes (definidos por taxa de ocorrência $\geq 5 / 1.000$ pacientes/ano) ${ }^{7}$. Essa ferramenta desenvolvida pelos médicos de família é parte integrante da agenda da Organização Mundial da Saúde (WHO - Family International Classification) ${ }^{6}$, entretanto necessita ganhar mais espaço na prática e nas pesquisas em APS no Brasil.

A presente edição contribui para essa discussão trazendo três artigos - um de Portugal e dois do Brasil - que abordam o tema da CIAP. O primeiro, Tendência de classificação no Capitulo Z da CIAP-2 entre 2006 e 2011 em um centro de saúde de Medicina Familiar em Coimbra, Portugal, faz uma reflexão sobre o aumento do uso de códigos referentes a problemas sociais, que talvez reflita a crise econômica pela qual está passando Portugal. Já os artigos dos autores brasileiros versam sobre a aplicabilidade da CIAP como ferramenta de estudo da demanda em APS. O artigo A methodological proposal to research patients' demands and pre-test probabilities in a paper form in primary care settings oferece uma ferramenta metodológica prática para o desenvolvimento de pesquisa usando a CIAP e formulários de papel e o artigo Assessment of pre-test probability in Primary Health Care using International Classification of Primary Care 2 (ICPC -2) refere-se à aplicação dessa metodologia em um serviço da APS brasileira. Convém ressaltar que a maioria das pesquisas realizadas na APS foram produzidas em uma era em que a coleta de dados era feita em papel, mesmo assim, pioneiros como William Pickles - em sua descrição das doenças infecciosas - são exemplos de como a pesquisa em APS auxiliou a modificar a face da medicina ${ }^{8}$. Desse modo, esses artigos visam possibilitar, mesmo em serviços de APS sem o uso de prontuários eletrônicos, o desenvolvimento de pesquisas que possam contribuir para o entendimento da realidade local de saúde. Como afirmou Bentsen?"

[...] na prática médica, um diagnóstico é um rótulo que anexamos às pessoas enfermas. Usamos esses rótulos como a base prática para o tratamento e, se possível, para o diagnóstico. Se as terminologias diagnósticas estão relacionadas com a necessidade de pesquisa, então elas adquirem uma outra dimensão. Elas passam a ser ferramentas necessárias para a análise dos problemas, ou seja, para a pesquisa em epidemiologia, na clínica, nos processos operacionais ou na medicina social.

De acordo com Starfield ${ }^{1}$, no intervalo de um ano, $75 \%$ a $85 \%$ da populaçáo necessitam apenas de cuidados primários de saúde, sendo que, do remanescente, $10 \%$ a $12 \%$ precisam de cuidados secundários e $5 \%$ a $10 \%$ requerem cuidados terciários, ou seja, a grande maioria dos pacientes recebe atendimento médico em ambulatório ou clínicas da atenção primária à saúde. Entretanto, a maior parte das pesquisas ocorre fora desses cenários de prática, criando uma distorção que dificulta a boa prática em medicina de modo geral e na medicina de família em particular ${ }^{4}$.

Por fim, espera-se que a leitura do conteúdo da presente edição possa ser inspiradora para futuras pesquisas nos contextos da APS e dos MFCs. 


\section{Referências}

1. Starfield B. What is primary care? Lancet. 1994; 344(October): 1129-33. http://dx.doi.org/10.1016/S0140-6736(94)90634-3

2. Jones R. Primary care research: ends and means. Fam Pract. 2000 Feb; 17(1): 1-4. http://dx.doi.org/10.1093/fampra/17.1.1

3. Checkland K. National Service Frameworks and UK general practitioners: street-level bureaucrats at work? Sociol Health IIIn. 2004; 26(7): 951-75. http://dx.doi.org/10.1111/j.0141-9889.2004.00424.x

4. Westfall JM, Mold J, Fagnan L. Practice-Based Research - "Blue Highways" on the NIH Roadmap. JAMA. 2007; 297(4): 403-6. http://dx.doi. org/10.1001/jama.297.4.403

5. Jaye C. Doing qualitative study in general practice: methodological utility and engagement. Fam Pract. 2002;19(5):557-62. http://dx.doi.org/10.1093/ fampra/19.5.557

6. Lamberts H, Wood M. The birth of the International Classification of Primary Care (ICPC). Serendipity at the border of Lac Léman. Fam Pract. 2002 Oct; 19(5): 433-5. http://dx.doi.org/10.1093/fampra/19.5.433

7. Wood M, Lamberts H, Meijer JS, Hofmans-Okkes IM. The conversion between ICPC and ICD-10. Requirements for a family of classification systems in the next decade. Fam Pract. 1992 Sep; 9(3): 340-8. http://dx.doi.org/10.1093/fampra/9.3.340

8. De Lusignan S, Van Weel C. The use of routinely collected computer data for research in primary care: opportunities and challenges. Fam Pract. 2006 Apr; 23(2): 253-63. http://dx.doi.org/10.1093/fampra/cmi106

9. Bentsen BG. Classifying of health problems in primary medical care. J R Coll Gen Pract Occas Pap. 1976; (1): 1-5. 